\title{
UNA GEOMETRÍA CONCEPTUAL
}

\section{LA NARRATIVIDAD DE LOS CUADROS VS. LA ESTRUCTURA VISUAL DE LA NOUVELLE}

\section{Mercédesz Kutasy}

Universidad Eötvös Loránd

mkutasy@gmail.com

Resumen: Este estudio es un experimento para observar si los mecanismos y estructuras que rigen el género de la novela corta son aplicables a los géneros visuales. Me interesa ver si es posible narrar con la imagen y si es posible hacerlo acorde a los principios establecidos por Ricardo Piglia en su "Secreto y narración. Tesis sobre la nouvelle". Desde el lado de la imagen me apoyaré en teorías de Wendy Steiner, Norman Bryson o de Nelson Goodman.

Palabras clave: narración visual, repetición, secreto, etcétera, ut pictura poesis

\section{A CONCEPTUAL GEOMETRY NARRATIVITY OF PAINTINGS VS. THE VISUAL STRUCTURE OF THE NOUVELLE}

\begin{abstract}
This paper is intended as an experiment to observe if it is possible to apply procedures and structures that regulate the nouvelle, to visual genres. I'm interested in examining if it is possible to narrate with an image, and to do so according the principles established by Ricardo Piglia in his "Secreto y narración. Tesis sobre la nouvelle". On the other hand, from the perspective of the image, I will base my arguments on theories presented by Wendy Steiner, Normar Bryson, and Nelson Goodman.
\end{abstract}

Keywords: visual narration, repetition, secret, etcetera, ut pictura poesis

DOI: https://doi.org/10.24029/lejana.2020.13.432

Recibido: el 24 de noviembre de 2018

Aceptado: el 1 de marzo de 2019

Publicado: el 19 de febrero de 2020 
Hace poco le pregunté a un amigo pintor qué grandes son los lienzos que va a colgar en la próxima exposición. "No son grandes, solo de unos 160x200cm." El orfebre Vladimir Péter a su vez definió la joyería como una especie de escultura, con variantes en la escala. Podría decirse entonces que una joya es, sin lugar a dudas, "pequeña"; y, sin embargo, el artista dice: "una joya sí tiene limitaciones espaciales. Por ejemplo, el que la lleva tiene que caber por una puerta" (Veiszer: en línea, traducción mía). Es grande, entonces... Pero no ironicemos sobre la relatividad del tamaño como categoría estética, aceptemos por el momento la observación del citado orfebre que opinaba que las dimensiones físicas del objeto no determinan el género de la obra, más bien, apuntan a su función. El objeto no ha de ser pequeña o grande, sino puntual, es decir, acorde a la metáfora de Quiroga, tiene que llegar todo recto en su blanco.

En la literatura, parece, ocurre algo semejante: en la clásica división de cuento, novela corta y novela, la extensión es nada más un detalle adicional y accidental, sin embargo, en todo momento sigue siendo detalle que no determina, tal vez, solo sugiere el género. Al mismo tiempo, la puntualidad, la elaboración acorde a la meta que una obra literaria anhela, sí es un factor clave para poder definir su pertenencia. Ricardo Piglia exige de la novela corta que tenga un secreto que en la mayoría de los casos no se revela nunca, a su vez, define la repetición como característica clave de las narraciones pertenecientes a este género.

En las páginas que siguen, no pretendo verificar ni rechazar la validez de la teoría de Piglia, más bien me propongo un experimento: a base de ideas tomadas del ensayo de Piglia, trataré de ver cómo funcionan (si es que funcionan) estos criterios en las artes plásticas. ¿Existirá la narratividad en las obras visuales? ¿Cómo narra un cuadro? ¿Podemos buscar la temporalidad en un género que se desarrolla en el espacio? Y si las dimensiones físicas del cuadro no importan, ¿qué es lo que influye la extensión de la narración visual?

Norman Bryson afirma que la historia del arte occidental es la historia de las carencias: la escultura prescinde de la textura y del color, la pintura, de la masa y ambas, del tiempo (1980: XVI). Y si no hay tiempo, no hay narración. Sin embargo, se me ocurre un mosaico de la Basílica San Vitale de Rávena que representa varias historias de la vida de Abraham en una sola escena. La secuencia empieza con la visita de los tres ángeles en casa de Abraham: los ángeles ya están sentados a la mesa, Sara desde una casita observa si los panes que ella preparó en un momento anterior de la historia les gustan a los visitantes; Abraham, a la izquierda de la escena lleva carne a la mesa - sabemos que al final de esta escena los ángeles prometerán a Abraham que en un año tendrá un hijo- - Y al otro lado de la mesa, la historia sigue y ya vemos a Isaac a punto de ser sacrificado: Abraham levanta la mano con una espada, pero la mano de Dios casi la agarra desde el cielo y se ve también el cordero entre la mesa de los ángeles y la segunda figura de Abraham que sustituirá a Isaac en el sacrificio. Varios años de acontecimiento en una sola escena, parece que sí es posible.

Wendy Steiner sugiere que la capacidad de una representación visual para narrar está estrechamente ligada a la posición del espectador. Según explica, la invención de la perspectiva renacentista en este aspecto supone una ruptura que para largo tiempo acaba con la narración: el punto de fuga presupone un espectador fijo que no se mueve de su posición previamente establecida por el artista; ahora, si el espectador no se mueve (según la intención del artista, este tiene que captar la escena con una sola mirada) y el cuadro tampoco, no hay posibilidad para insertar el tiempo en el acto de la percepción. La "narración" en estos casos se ve sustituida por alusiones literarias (símbolos, poses dramáticos, títulos) en el cuadro que 
por naturaleza implican una historia, es decir, contienen el tiempo que acaba de ser sacrificado en aras de la verosimilitud. Estos cuadros suelen representar, en vez de una secuencia narrativa, un momento fértil (pregnant moment) que es la acción frenada en su clímax. Es decir, no se presentan ni los antecedentes ni las consecuencias de la misma, y el momento más significativo se convierte en sustituto (una especie de símbolo) de toda la narración que, a su vez, se omite.

Piglia dice que una novela corta es un cuento narrado varias veces, a la vez, para que un cuadro pueda llamarse narrativo, igualmente es imprescindible que presente al menos dos momentos temporales sucesivos, que sea protagonizado por un sujeto que se repite y que la historia se desenvuelva en un ambiente mínimamente verosímil. La repetición del sujeto que protagoniza las escenas es garantía del paso del tiempo (la misma figura no puede multiplicarse en el mismo momento en una escena verosímil) a la vez que supone un hilo unificador que señala la relación causa-efecto entre las representaciones aparentemente aisladas. Nelson Goodman interpreta con razón el cambio de la distrubución espacial de las figuras como cambio temporal entre los acontecimientos representados.

La causalidad como criterio aristotélico de la épica es otro punto cardinal a la hora de hablar sobre "narraciones" visuales: para que entendamos una serie de imágenes como historia, hace falta tener la noción de que lo visto en un cuadro es causa de lo visto en el cuadro siguiente. Si falta la figura que unifique las escenas consecutivas, el espectador (o en literatura el lector) ha de inventar estrategias interpretativas para encontrar la causalidad latente. Chatman en Story and Discourse cita el ejemplo de E.M. Forster: "Murió el rey y luego la reina también murió de tristeza" (1980: 34) y observa que para concebir la frase como narración hace falta suponer una relación entre los personajes (que la reina sea esposa del rey muerto), eso es, hace falta que el rey se incorpore en la afirmación hecha sobre la reina. Wendy Steiner a su vez afirma que ser personaje en un discurso visual significa ser figura que se repite: las figuras que no participan en los acontecimientos y, por tanto, no se repiten, se limitan a ser tan solo elementos del decorado.

Otro problema de las artes plásticas es que, mientras la lectura de un texto literario es lineal, la pintura no tiene dirección, con las palabras de Steiner, los cuadros son laberintos visuales sin un sendero lineal que lleve a través de ellos; por tanto, el pintor ha de guiar el ojo del espectador para que su narración se desarrolle en el orden que él había considerado oportuno. Para lograrlo mencionamos nada más dos soluciones frecuentes: la metáfora del sendero de la vida, donde la secuencia de los acontecimientos se representa en orden cronológico a medida que el protagonista (generalmente un santo) va avanzando a lo largo de un sendero para llegar a su meta que suele encontrarse en un primer plano; además, los episodios pueden aparecer también en diferentes salas de un edificio (en las predelas de los altares, por ejemplo). El edificio en sí es un espacio a caballo entre lo puramente espacial y lo narrativo: el espectador capta la masa del edificio con una sola mirada y, en este sentido, la arquitectura participa de los anhelos unificadores de la perspectiva renacentista; mientras que comprender todos los espacios de un edificio, entender la relación entre las diferentes partes del mismo (y captar, tal vez, la decoración pictórica en el interior) requiere desplazamiento de parte del espectador, tiene una dirección y ocupa un tiempo que puede considerarse sin falta narrativo. 
El edificio y sus cuartos consecutivos son, entonces, lugares para que lo espacial obtenga el tiempo; por otra parte, Piglia habla de la necesidad de un lugar para que el secreto se materialice: la casa de las portuguesas en Los adioses, por ejemplo. Curiosamente, vemos que la casa es un elemento esturcturador de carácter eminentemente espacial en la narrativa, a la vez que es un recurso que reviste del tiempo las secuencias visuales de las artes plásticas. La casa, también, es frecuentemente el lugar del secreto que, según Piglia, abarcaría la laguna alrededor del cual se desenvuelven los repetidos discursos (o silencios) de la novela corta. Es "un lugar vacío que permite unir tramas narrativas diversas y personajes distintos que conviven en un espacio atados por ese nudo que no se explica. Porque si se explica, hay que escribir una novela" (2006: 200). ¿Cómo aparece este vacío en las artes visuales figurativas? Nelson Goodman menciona una pintura de Sassetta que representa El encuentro de San Antonio y San Pablo, usando la imagen ya mencionada del sendero de la vida.

El sendero es un recurso lógico porque aparte de su contenido metafórico que implica recorrer una trayectoria vital y llegar a una meta anhelada, visualmente sirve para guiar el ojo del espectador. La composición del cuadro de Sassetta está diseñada para que partamos con el santo desde el fondo, del lado izquierdo para llegar a un primer plano donde el sendero se ensancha y se abre una puerta en frente de nosotros. La dirección a seguir igualmente está indicada a través de la postura de San Antonio: hacia donde él mira y se dirige, se dirige igualmente el ojo del espectador.

La diminuta figura del santo aparece por primer vez en el rincón superior izquierdo, pasa por detrás de una colina, se encuentra con un centauro pagano al que le reprocha y le convence de la necesidad de mejorar su vida y al final, en la parte baja del primer plano abraza a modo de saludo al otro santo, dejando atrás el tenebroso bosque que es la copia en miniatura de la 'selva oscura' de los primeros versos de la Divina Comedia. [...] Los ojos cruzan el mundo imaginario de la imagen; el movimiento acorde a la representación puede evocar la ilusión del paso real del tiempo; el elemento tiempo puede provocar la sensación de la autenticidad de la narración. Finalmente, la narrativa podrá enriquecer el significado de la experiencia espiritual. (Seymour: 18, 23; la traducción es mía)

El camino del santo, como hemos visto, desaparece varias veces de los ojos del espectador: no lo vemos cuando pasa por detrás de la colina, lo interrumpe el borde del cuadro, se esconde en el bosque; como afirma Wendy Steiner, la fragmentación y a veces desaparición del sendero es la analogía de la vida sufrida del santo que al final, en el primer plano del cuadro, encuentra el amor cristiano.

La figura de San Antonio aparece tres veces en el cuadro y, aunque se puede seguir con claridad por dónde pasa el sendero, la mayoría de su trayecto queda invisible a los ojos del espectador. Estas partes invisibles serían, a mi modo de ver, los puntos suspensivos, la etcétera característica de la novela corta. Aparece la figura que se repite (el santo), hay un indicio del discurso repetido también (los dos actos de caridad: convertir al cristianismo al centauro y abrazar al otro santo), y está el enigma, el bosque y la colina, tras los que el espacio oculto puede albergar otras tantas historias análogas que complementarían la narración de lo que es una vida entera. Steiner a su vez afirma que la composición gótica del cuadro de Sassetta (y creo que lo gótico en este caso alude sobre todo a la composición simultánea y a la omisión de las leyes de la perspectiva) obra a favor de la narración, eso es, que el realismo de la representación es de sentido opuesto a la narratividad. 
Para una narración visual, como acabamos de ver, hace falta la repetición de personajes, pero también de formas, tipos iconográficos, colores y símbolos; para la narración en la novela corta, según Piglia, es igualmente imprescindible la etcétera, la serialidad de acontecimientos análogos. Se me ocurre nada más el índice de la obra de Arqueles Vela, La señorita Etcétera, ${ }^{l}$ que es una lista hecha de otras listas: una serie de números $(1,2,3,4,5,6$, $7,8,9,10)$, una repetición en el tiempo ("Todos los días, a la misma hora..."), otra de formas ("Mi sombra..."), de recuerdos ("Cada vez que su recuerdo...") y citas ("Mis evocaciones estaban..."); cada uno de los títulos de capítulo, terminado en otros puntos suspensivos que en la misma primera página empujan al lector a un abismo de series que no paran de multiplicarse y nunca acaban.

¿Puede imaginarse esta misma serie abismal en una obra de arte visual? Sin lugar a dudas, se nos ocurren los laberintos matemáticos de Maurits Cornelis Escher. Sin embargo, ¿será posible encontrar una estructura semejante a la de la novela corta en estos cuadros virtuosísimos? Para distinguir una lista basada en la etcétera de aquella estructura que especifica Piglia, es imprescindible hacer también una distinción entre lo que Steiner llama diseño y figura. Según su propuesta, diseño sería cuando los motivos análogos que aparecen en un cuadro se repiten periódicamente, formando un infinito rítmico, mientras que la aparición de la figura (sin la cual la estructura de la novela corta no sería posible) supone cierta individualización a la vez que su presencia requiere un principio y un final. Para ilustrar su tesis, Steiner recurre a un cuadro del mismo Escher, El encuentro (1944), que interpreta como "parábola de la comprensión racial" ("parable of racial understanding") y ejemplo de la "soberanía blanca" ("with somewhat white-supremacist overtones") (1988: 20, traducción mía), aunque el mismo Escher lo explica como un encuentro/conciliación entre un personaje optimista y otro pesimista (1992: 11), características que efectivamente se reflejan en sus caras. En el fondo del cuadro, las figuras se representan bidimensionales y son de carácter repetitivo: los bordes de la litografía se ven borrosos, las figuras se desdibujan, no se aprecia con exactitud donde empieza el dibujo del diseño. A su vez, en el centro vemos una especie de círculo (Steiner lo llama podio), alrededor del cual las figuras blancas y negras respectivamente salen de su bidimensionalidad para seguir la línea de este círculo. A medida que van avanzando hacia el primer plano del cuadro, se muestran desde múltiples puntos de vista hasta encontrarse abajo, en el medio, donde se estrechan la mano. Steiner afirma que después de este momento la secuencia no puede avanzar más, porque en este caso las figuras cambiarían de sitio ocupando el lugar del otro, e interpreta la litografía como el encuentro entre la secuencia narrativa y el llamado "momento fértil". Yo pienso que, aparte de lo expuesto por Steiner, la litografía de Echer muestra a la perfección el funcionamiento de la narración en la novela corta. Aparecen dos figuras, una blanca y otra negra; su aspecto físico funciona, según vimos, como sustituto visual de la narración (historia) y se repite varias veces, con leves modificaciones, desde diferentes puntos de vista (que serían el equivalente de las versiones narradas). A primera vista, la narración (el movimiento de las figuras) se desenvuelve en una trayectoria geométrica y cerrada (la circunferencia del primer plano) donde los acontecimientos (movimientos) empiezan en el punto donde las figuras cobran

\footnotetext{
${ }^{1}$ En la primera publicación de la obra (1922) no aparece el Índice que, sin embargo, figura en la edición actualizada. Véase: http://www.lanovelacorta.com/facsimiles.html.
} 
tridimensionalidad y terminan en el medio, con el encuentro de la figura blanca con la negra. Aun así no podemos no darnos cuenta de que el diseño que repite la forma de las figuras en dos dimensiones es infinito y al igual que el índice de la obra de Arqueles Vela, nos arranca a un abismo de forma de espiral (en vez de lo que sugiere la forma circular del podio). Este diseño infinito inmediatamente anula la certidumbre de que las dos figuras que se dan la mano en la mitad del cuadro suponen un fin, porque realmente no hacen otra cosa que abrir una puerta al abismo, y, efectivamente: detrás de la figura blanca en el medio aparece una sombra negra que mira y camina en la misma dirección, parece que la historia se repetirá una y otra vez más, el blanco se convertirá temporalmente en negro, el negro en blanco y así sucesivamente. El cuadro de Escher es, entonces, una secuencia infinita de repeticiones de las que el artista elige un segmento que desea presentar como algo particular con los recursos de la narración. Distingue un segmento a través de una estructura regular y dando personalidad (tridimensionalidad) a sus figuras, pero en todo momento vemos que tanto el principio como el final es aleatorio, la historia sigue y se repite infinitas veces.

Al principio de mi reflexión hablé de las carencias del arte occidental que menciona Norman Bryson: a pesar de la tradición del paragone, comparación tradicional entre los diferentes géneros artísticos y de tantos esfuerzos para prestar la pintura de la escultura y viceversa, los géneros visuales por naturaleza carecen del tiempo. A través de este breve experimento mi propuesta era brindar una especie de puente a través de la estructura de la novela corta: esta parece trascender las fronteras establecidas por Simónides de Ceos, compartiendo su estructura con la de la pintura narrativa. Si, según Simónides, la pintura es poesía muda y la poesía es pintura que habla, los ejemplos anteriormente observados pueden apuntar a decir que la novela corta sería, en este sistema, un cuadro que se hizo con el tiempo, un cuadro que narra.

\section{Fuentes}

BASÍliCA SAN VITALE, RÁVENA. Abraham en Mamré. Abraham y los tres ángeles. Mosaico, 521-547.

ESCHER, M. C. El encuentro. Litografía, Metropolitan Museum of Art, 1944.

IL SASSETTA (STEFANO DI GIOVANNI). El encuentro de San Antonio y San Pablo, 1440, National Gallery of Art, Washington.

VELA, Arqueles (2012): La señorita Etcétera. Coords. y eds. Gustavo Jiménez Aguirre y Gabriel M. Enríquez Hernández. Recuperado de http://www.lanovelacorta.com/novelas-en-campo-abierto/la-senorita-etcetera.html [20/01/2020].

\section{Bibliografía}

BRYSON, Norman (1981): Word and Image: French Painting of the Ancien Régime. Cambridge, Cambridge University Press.

CHATMAN, Seymour (1980): Story and Discourse. Ithaca, N.Y, Cornell University Press.

ESCHER, M. C. (1992): Grafikák és rajzok. Budapest, Kultúrtrade. 
GOODMAN, Nelson (1980): “Twisted Tales; Or, Story, Study and Symphony”. Critical Inquiry (7) 1 (Autumn 1980): 103-119. DOI: https://doi.org/10.1086/448090

PIGLIA, Ricardo (2006): "Secreto y narración. Tesis sobre la nouvelle". En Eduardo Becerra (ed.): El arquero inmóvil. Nuevas poéticas sobre el cuento. Madrid, Páginas de Espuma: 187-205.

SEYMOUR, JR, Charles (1961): Art Treasures for America: An Anthology of Paintings and Sculpture in the Samuel H. Kress Collection. London, Phaidon

STEINER, Wendy (1988): "Pictorial Narrativity". En su libro Pictures of Romance. Form against Context in Painting and Literature. Chicago/London, University of Chicago Press: 7-42.

VEISZER, Alinda: Entrevista a Vladimir Péter en el programa televisivo Záróra, 21/04/2010. Recuperado de https://nava.hu/id/976658/ [20/09/2018].

(C) Mercédesz Kutasy

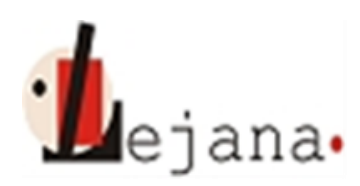

http://ojs.elte.hu/index.php/lejana

Universidad Eötvös Loránd, Departamento de Español, 1088 Budapest, Múzeum krt. 4/C 